\title{
The biology of cutaneous neurofibromas
}

\section{Consensus recommendations for setting research priorities}

Jean-Philippe Brosseau, PhD, * Dominique C. Pichard, MD, * Eric H. Legius, MD, PhD, Pierre Wolkenstein, MD, PhD, Robert M. Lavker, PhD, Jaishri O. Blakeley, MD, Vincent M. Riccardi, MD, Sharad K. Verma, PhD,

Isaac Brownell, MD, PhD, and Lu Q. Le, MD, PhD

Neurology ${ }^{\circledR}$ 2018;91 (Suppl 1):S14-S20. doi:10.1212/WNL.0000000000005788

\section{Abstract}

\section{Objective}

A group of experts in dermatology, genetics, neuroscience, and regenerative medicine collaborated to summarize current knowledge on the defined factors contributing to cutaneous neurofibroma ( $\mathrm{cNF}$ ) development and to provide consensus recommendations for future research priorities to gain an improved understanding of the biology of $\mathrm{cNF}$.

\section{Methods}

The group members reviewed published and unpublished data on $\mathrm{cNF}$ and related diseases via literature search, defined a set of key topic areas deemed critical in cNF pathogenesis, and developed recommendations in a series of consensus meetings.

\section{Results}

Five specific topic areas were identified as being relevant to providing an enhanced understanding of the biology of cNF: (1) defining the human cells of origin; (2) understanding the role of the microenvironment, focusing on neurons, mast cells, and fibroblasts; (3) defining the genetic and molecular differences between the cNFs, focusing on size and number; (4) understanding if sex hormones are critical for cNF development or progression; and (5) identifying challenges in establishing in vitro and in vivo models representing human cNF.

\section{Conclusions}

The complexity of cNF biology stems from its heterogeneity at multiple levels including genetic, spatial involvement, temporal development, and cellular composition. We propose a unified working model for $\mathrm{cNF}$ that builds a framework to address the key questions about cNF that, when answered, will provide the necessary understanding of cNF biology to allow meaningful development of therapies.

\author{
Correspondence \\ Dr. Le \\ lu.le@utsouthwestern.edu
}

\section{RELATED ARTICLES}

Creating a comprehensive research strategy for cutaneous neurofibromas

Page S1

Cutaneous neurofibromas:

Current clinical and

pathologic issues

Page S5

Considerations for development of therapies for cutaneous neurofibroma

Page S21

Clinical trial design for cutaneous neurofibromas Page S31

\footnotetext{
*These authors contributed equally to this work.
}

From the Department of Dermatology (J.P.B., L.Q.L.), UT Southwestern Medical Center, Dallas, TX; Dermatology Branch (D.C.P., I.B.), Center for Cancer Research, National Cancer Institutes of Health, Bethesda, MD; Human Genetics Department (E.H.L.), University of Leuven, Belgium; Division Cancer Immunity Transplantation Infections (P.W.), Paris Est Créteil University, France; Department of Dermatology (R.M.L.), Northwestern University, Chicago, IL; Department of Neurology (J.O.B., S.K.V.), The Neurofibromatosis Therapeutic Acceleration Program, The Johns Hopkins University School of Medicine, Baltimore, MD; and The NF Institute (V.M.R.), La Crescenta, CA.

Go to Neurology.org/N for full disclosures. Funding information and disclosures deemed relevant by the authors, if any, are provided at the end of the article. 


\section{Glossary}

CALM = café-au-lait macule; $\mathbf{c N F}=$ cutaneous neurofibroma; $\mathbf{E C M}=$ extracellular matrix; $\mathbf{G A P}=$ GTPase-activating protein; MPNST $=$ malignant peripheral nerve sheath tumor; NAF = neurofibroma-associated fibroblasts; NF1 = neurofibromatosis type $1 ; \mathbf{p N F}=$ plexiform neurofibroma; SKP $=$ skin-derived precursor cell; TGF- $\beta=$ tumor growth factor $-\beta$.

The clinical spectrum of neurofibromatosis type 1 (NF1) is broad and dependent on in which cell type the biallelic inactivation of the NF1 (Neurofibromin 1) gene takes place, such as melanocytes (café-au-lait macules [CALM]), osteoblasts (tibial dysplasia), and Schwann cells (cutaneous neurofibroma $[\mathrm{cNF}]$ and plexiform neurofibroma $[\mathrm{pNF}])$. Importantly, the 2 main types of neurofibroma ( $\mathrm{cNF}$ and $\mathrm{pNF}$ ) differ widely clinically. cNF typically become apparent around puberty and increase in number with age. They reside exclusively in the dermis and never progress to malignancy. In contrast, pNF are often congenital, and progress predominantly during childhood and adolescence. Although pNF can involve the skin, they are generally deep tumors involving nerve plexuses below the dermis and they carry a risk of sarcomatous transformation. Despite knowing that the NF1 syndrome and its manifestations are caused by mutation of the NF1 tumor suppressor gene, there is little understanding about why the multiple manifestations of NF1 occur in some people but not others and with variable severity, even within families.

The most common tumor in adults with NF1 is cNF, presumably resulting from the biallelic loss of NF1 in the Schwann cell lineage. cNF can vary widely in size (from millimeters up to few centimeters) and in numbers (from a few to thousands that can cover most of the skin surface) and can develop in virtually any location of the body. In addition to the important psychosocial consequence of $\mathrm{cNF}$ tumors, irritation, bleeding, pain, and superficial infections are unmet clinical needs. There are no preventative measures, and the only treatment options are surgical.

Researchers interested in understanding cNF biology face multiple critical challenges. First, the human NF1 gene and its mRNA are relatively large ${ }^{1}$ and difficult to manipulate into expression vectors. Therefore, the biochemistry of the different protein domains of NF1 (except for the GTPase-activating protein [GAP] domain) is not well-understood. ${ }^{2}$ Second, cNF are slow-growing, noncancerous tumors. Consequently, isolating and maintaining primary cultures from $\mathrm{cNF}$ is difficult. Third, the generation of robust $3 \mathrm{D}$ in vitro culture systems ${ }^{3}$ and in vivo models ${ }^{4}$ are notoriously challenging. In an effort to address these gaps, based on existing data from both $\mathrm{cNF}$ and $\mathrm{pNF}$ literature, this group sought to identify the key gaps in the understanding of cNF biology that require investigation in order to accelerate the development of effective therapies for these tumors.

\section{Methods}

A literature review was conducted including the terms NF1, cNF, dermal neurofibroma, $\mathrm{pNF}$, genotype, phenotype, mast cell, macrophage, fibroblast, fibrosis, hormones, development, and animal models in an effort to identify all published literature that may be relevant to the general topics of cNF initiation, development, and progression. The working group was composed of experts in Schwann cell biology, genetics, dermatology, stem cell biology, fibrosis, regenerative medicine, and NF1 clinical care. Working group members reviewed published and unpublished data around the set of topic areas individually and as a group during a series of meetings facilitated over a 4-month period, prioritized key questions, and established consensus recommendations for each topic area.

\section{Results}

\section{Defining the human cells of origin}

Theoretically, the cell of origin is the cell that first undergoes NF1 biallelic inactivation, regardless of the timing of this event. Identification and isolation of the human cells of origin would allow reconstruction of the biological steps leading to tumor initiation and progression ultimately leading to identification of targets that may be susceptible to therapeutic intervention.

Several groups have reported a putative cell of origin for cNF. Karvonen et al. ${ }^{5}$ proposed that cNF originate from human hair follicle stem cell-like neurofibroma precursor cells. However, patients with NF1 also develop cNF on the palms and soles where there are no hair follicles (figure 1). Le et al. ${ }^{4}$ observed pNF when $\mathrm{Nf1}^{-/-}$skin-derived precursor cells (SKPs), a population of neural crest-derived progenitors in the murine dermis, were implanted into the injured sciatic nerve of immune compromised mice. However, cNFs only developed when these cells were implanted in the skin of hormone-primed recipients or in a topically inducible model deleting Nf1 locally in the skin. ${ }^{4}$ Of note, biallelic inactivation of $\mathrm{Nf1}$ in pNF models does not robustly lead to $\mathrm{CNF}$, supporting a hypothesis that the cells of origin of $\mathrm{cNF}$ and $\mathrm{pNF}$ are different. Interestingly, Gresset et al. ${ }^{6}$ reported that the Schwann cells of the dermal nerve endings have a different origin compared to the majority of the other Schwann cells. Intriguingly, these neural crestderived stem cells are reminiscent of the $\mathrm{SKPs}^{4,7}$ and suggest that they may be the embryonic source of the $\mathrm{CNF}$ cell of origin. In this sense, identifying mouse Cre lines that are expressed in the subpopulation of SKPs that give rise to $\mathrm{CNF}$ will be instrumental to our understanding of cNF biology. Other indirect evidence supporting the differential origin of $\mathrm{cNF}$ and $\mathrm{pNF}$ comes from experiments aiming to elucidate the contribution of skin or nerve trauma in the development of neurofibroma. 

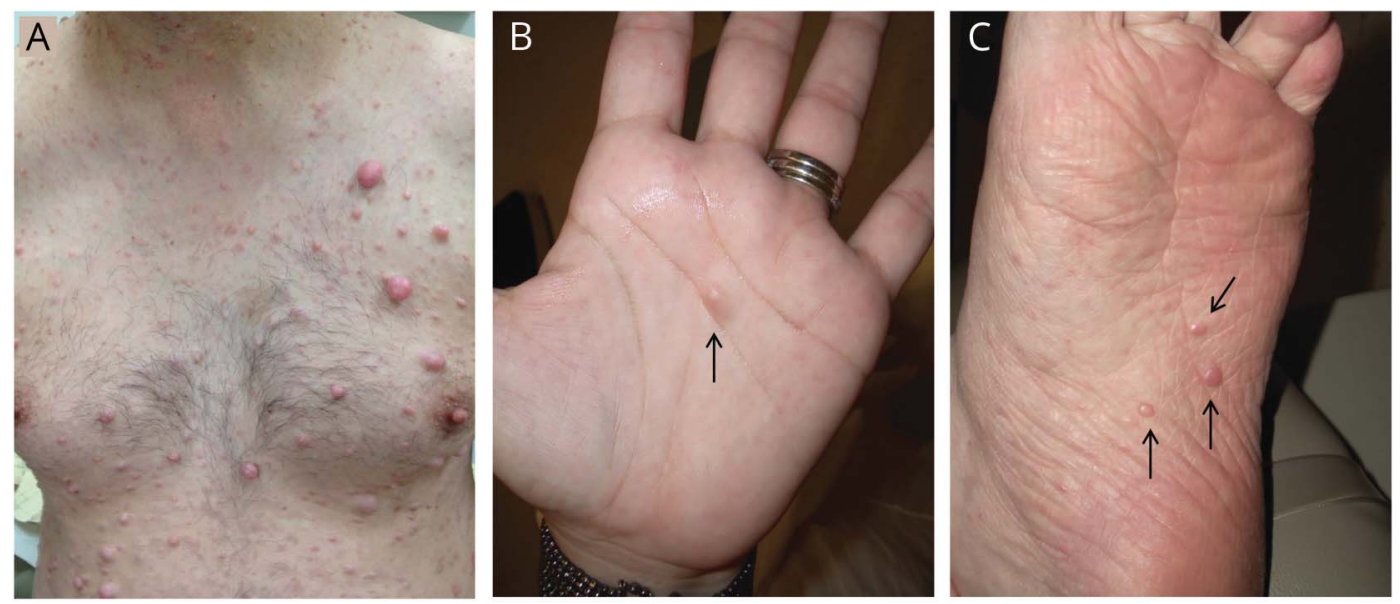

Cutaneous neurofibromas can develop on hair-bearing skin (A) or non-hair-bearing skin on the palm (B) or sole (C) (arrows).

Strikingly, cNF was never observed in an injured sciatic nerve-dependent pNF mouse model where deep skin incision was performed. This suggests that wounded small nerve endings do not behave like the sciatic nerve in their ability to promote neurofibroma. Directly assessing the effect of dermal nerve injury in existing ${ }^{4}$ or novel cNF mouse models will help clarify the role of injury in cNF formation. Importantly, the cell of origin of cNF may encompass melanocytes as skin hyperpigmentation completely covers some $\mathrm{cNF}$ (diffuse cNF). Some cNF present with redness or purplish hue, likely due to tumor vascularization (figure 1). Collectively, these data and observation indicate a need to better characterize the types of nerve associated with $\mathrm{cNF}$ and $\mathrm{pNF}$ regarding their intrinsic tumorigenic properties and determine if there is evidence supporting the hypothesis that $\mathrm{cNF}$ and $\mathrm{pNF}$ have distinct cellular origin.

\section{Understanding the tumor microenvironment}

The cell types found in either human cNF or pNF are virtually the same as the cell types found in healthy peripheral nerves except they are mingled in a collagen-rich, fibrotic extracellular matrix (ECM) and are highly disorganized. Current data suggest that the most important cellular components for development and maintenance of cNF are the nerve, immune cells (e.g., mast cells), and fibroblasts.

Normal Schwann cells require nerve contact during development. ${ }^{8}$ Adameyko et al. ${ }^{9}$ described the migration of Schwann cell precursors (SCPs) along growing nerves, and demonstrated that the association with nerves influences the fate of the precursor cells. In the context of neurofibroma, Liao et al. $^{3}$ demonstrated that murine Nf1-deficient SKPs more readily give rise to $\mathrm{pNF}$ when injected into nerve tissue, but they did not develop pNF when injected into non-nerve tissue. Further work is needed to clarify if human cNF may also require contact with nerves or factors such as Neuregulin
1 (NRG1) in the perineurial microenvironment for their development and maintenance (figure 2).

The immune cells that contribute to cNF are mast cells and macrophages. Mast cells are histamine-secreting granulocytic cells known for their involvement in allergic reactions. Mast cell infiltration is one of the histologic hallmarks of neurofibroma. ${ }^{10}$ A working model of tumorigenesis derived from experiments conducted mainly using a mouse pNF model proposes Schwann cell-mast cell-fibroblast paracrine signaling (figure 2). ${ }^{11}$ Specifically, the Parada laboratory showed that the Krox20Cre $\mathrm{Nf1}^{\mathrm{f} /-}$ pNF mice only developed $\mathrm{pNF}$ in a $\mathrm{Nf1}^{+/-}$background, supporting the hypothesis that non-Schwann cell types are sensitive to Nf1 gene dosage and may play an important role in pNF development. ${ }^{12}$ Subsequently, the Clapp laboratory showed that deletion of Nf1 in Schwann cells induces a higher secretion of stem cell factor which in turn recruits $\mathrm{Nfl}^{+/-}$mast cells through kit receptor activation. ${ }^{13}$ Hypermotile $\mathrm{NfI}^{+/-}$mast cells subsequently activate $\mathrm{Nfl}^{+/-}$fibroblasts and stimulate their collagen deposition through tumor growth factor- $\beta$ (TGF- $\beta$ ), ${ }^{14}$ explaining a second hallmark of human pNF: abundant collagen deposition. ${ }^{11} \mathrm{How}-$ ever, it is not clear to what extent these data can be extrapolated to human cNF. Clinical application of these findings via a Kit receptor inhibitor or mast cell stabilizer showed only modest results in clinic for $\mathrm{pNF}^{15,16}$ One possibility is that the pNF mouse model is more dependent on the Schwann cell-mast cell axis than human pNF. Also, these models did not account for macrophages that are commonly found in cNF. Although infiltration of macrophages correlates with tumor progression, their exact role in neurofibroma tumorigenesis is not well-understood. ${ }^{17}$

Finally, fibroblasts are nonepithelial, noninflammatory, and nonvascular cells of the connective tissue responsible for ECM deposition and reorganization. ${ }^{18}$ Upon skin injury, the normal wound repair process includes inflammation followed by fibroblast proliferation, re-epithelization, and ECM remodeling. 


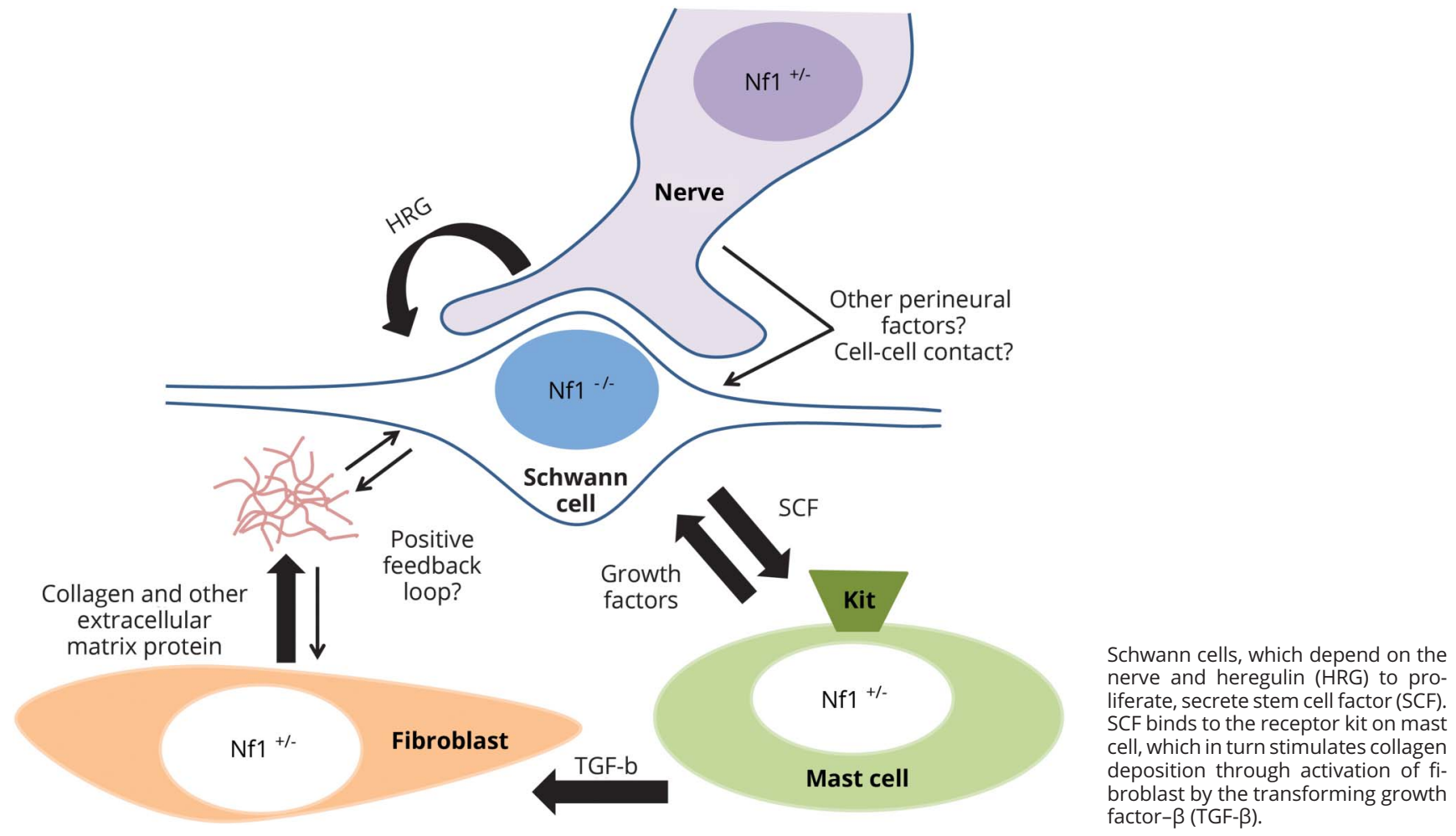

Fibrosis, defined as formation of excess connective tissue in an organ, occurs during the second phase of healing. High levels of collagen deposition, as well as the expression level of key components of the TGF- $\beta$ pathway in activated fibroblasts, are surrogates often used to quantify the extent of fibrosis. No treatment is currently able to reverse fibrosis, but drugs inhibiting the TGF- $\beta$ pathway are under investigation for this purpose. $^{19}$

Neurofibroma-associated fibroblasts (NAFs) are abundant in cNF, where up to $50 \%$ of human cNF dry weight is collagen and NAFs display abnormal collagen deposition, all hallmarks reminiscent of fibrosis. ${ }^{20}$ However, initial attempts to verify the role of fibroblasts in human pNF by pharmacologically targeting fibroblast-producing collagen have had limited success. $^{21,22}$ One explanation is that NAFs may not be the typical activated fibroblast cell characterized in major organ fibrosis and cancer contexts. Indeed, NAFs do not express fibroblast markers observed in other cutaneous disorders like dermatofibrosarcoma protuberans ${ }^{23}$ or keloid, ${ }^{24}$ and are negative for smooth muscle actin, a classic marker for activated fibroblasts. ${ }^{25}$ Alternatively, collagen-producing fibroblasts may not be functionally equivalent in $\mathrm{cNF}$ and $\mathrm{pNF}$. Overall, multiple questions remain about the role of NAFs in cNF pathogenesis.

An interesting theory that bridges the hypotheses of fibrosis, neurofibroma formation, and a hyperactive immune response is that neurofibromas may develop in the setting of trauma. ${ }^{26,27}$ Indeed, nerve injury initially attracts immune cells such as macrophages (to clear cellular debris during Wallerian degeneration ${ }^{28}$ followed by mast cells (likely to increase capillary permeability). ${ }^{29}$ Specifically in the context of the peripheral nerve system, proliferating fibroblasts and Schwann cells are aligned in an ordered column (also known as band of Bungner) to bridge the gap between the distal and proximal nerve, allowing guidance for axonal regrowth. ${ }^{30}$ Finally, the ECM is slowly remodeled to eventually reach normal architecture. In the context of neurofibroma, one can envision that the high number and proliferative status of Schwann cells triggered by nerve injury and loss of axonal contact would significantly increase the likelihood of biallelic NF1 inactivation. How the ECM produced by fibroblasts and the recruited immune cells initially aiming at healing the nerve would then turn into a fibrotic microenvironment preventing the nerve to heal is currently unknown. What is increasingly clear is that for the best chance of effective therapeutics, prior to investigating treatments targeting various elements of the cNF microenvironment, a better understanding of the relative contributions of each of these various cells to tumorigenesis is needed. This will entail (1) identifying specific markers for each cell type described and their relative number and function in various phenotypes of $\mathrm{cNFs}^{31}$ and (2) the development of reliable in vitro and in vivo model systems that recapitulate human $\mathrm{cNF}$ progression to allow omission of specific cell types and enable pharmacologic/genetic interventions. ${ }^{6}$ 
Other cell types in the microenvironment of $\mathrm{cNF}$ include pericytes, and cellular components comprising the nerve perineurial barrier, but their role is unclear. ${ }^{32}$ Of note, keratinocytes, melanocytes, and other cells from the skin structures (e.g., sebaceous gland, hair follicle, and eccrine gland) can be found at the margin of $\mathrm{cNF}$ but not within the tumor bulk. Finally, it is possible, but uncommon, to find abundant adipocytes or fat-like cells in neurofibromas. ${ }^{33}$

\section{Defining the genetic and molecular differences between the cNFs: Focus on size and number}

There is extensive interpatient and intrapatient heterogeneity in the presentation, degree of severity, and behavior over time of cNF. Efforts at defining genotype-phenotype correlations in NF1 in general and relative to cNF have largely been fruitless, with 3 notable exceptions. The first 2 exceptions are specific NF1 gene mutations that result in a very low incidence of cNF or pNF (c.2970-2972delAAT; p.992delM ${ }^{34}$ and R1809 NF1 mutations ${ }^{35}$ ) and the third results in a higher likelihood of early development and higher number of cNF (large NF1 gene deletions). ${ }^{36}$ It would be highly informative to validate the biochemical and biological consequences of mutated neurofibromin to better understand how these first 2 mutations "suppress" cNF development. Specifically, how do these changes alter $3 \mathrm{D}$ protein structure, influence sites for binding partners, or affect subcellular localization of neurofibromin? Even more intriguing is that this mild cutaneous phenotype is indistinguishable from Legius syndrome, which is caused by mutations in the Ras signaling regulator SPRED1, 37,38 suggesting the major influence of this mutation is via the modulation of the Ras signaling pathway in melanocytes and other cells, but not significantly in Schwann cells. Further, these 2 mutations do not directly implicate the GAP domain of neurofibromin, so it is unclear how mutations at R1809 or c.29702972delAAT would affect the Ras signaling inhibitory capacity of neurofibromin. Elucidating the mechanism behind the lack of development of $\mathrm{cNF}$ in patients with mutations in NF1 R1809 or NF1 c.2970-2972delAAT could be groundbreaking for new therapeutic approaches for $\mathrm{cNF}$.

In sharp contrast, around $5 \%-10 \%$ of NF1 patients have a large deletion encompassing the NF1 gene, which is associated with a high number of $\mathrm{cNF}$ and an increased risk for malignant peripheral nerve sheath tumor (MPNST). The genetically linked SUZ12 gene has been identified as an important modifier of NF1 in MPNST. ${ }^{39}$ It is unknown if SUZ12 or any other gene that is commonly inactivated with NF1 in the setting of these large gene deletions plays a role in determining the number, size, or timing of onset of $\mathrm{cNF}$.

Outside of these examples, for the majority of NF1 DNA mutations, the predicted functional consequence at the RNA and protein levels is unknown, contributing to the lack of genotype-phenotype correlation. By systematically annotating the RNA and protein effects due to different NF1 mutations in tissues and cells from NF1 patients, ${ }^{40-42}$ one can begin grouping together apparently unrelated mutations. ${ }^{43,44}$
An even better approach is systematic functional profiling of mutant neurofibromin. Scoring the effect on Ras signaling may help reclassify discordant results, generating new hypotheses about the role of neurofibromin outside its GAP domain and new mechanistic insights for cNF development.

There is often wide variation of cNF tumor size and concentration on patients' bodies, suggesting that either tumor growth is under the influence of unidentified stochastic modifiers or not all somatic mutations (the second hit mutation) leading to biallelic loss of NF1 are equivalent. In support of the latter hypothesis, the mutational landscape of cNF across 40 tumors from 11 patients revealed that the nature of the second hit mutation in NF1 is different in each tumor. ${ }^{45}$ It is currently unknown if there are different forms of $\mathrm{cNF}$ or if there are relatively few types of $\mathrm{cNF}$ that appear phenotypically distinct because they are observed at various stages along a growth continuum. ${ }^{31,46}$ A challenge is that $\mathrm{cNF}$ may not be visible at early stages and some patients report that cNF erupt over very short intervals. Hence, researchers investigating factors that explain the heterogeneity of $\mathrm{cNF}$ should be mindful that we do not yet have an adequate understanding of the natural history of cNF in humans.

\section{Understanding if sex hormones are critical for cNF development or progression}

There have been many proposed factors that influence the development and growth of $\mathrm{cNF}^{31,46}$ One of the more pervasive hypotheses is that pregnancy or other periods of systemic hormonal shifts stimulate cNF appearance and growth. Dugoff and Sujansky ${ }^{47}$ retrospectively surveyed 105 women with NF1 who had a history of at least one pregnancy to assess perceived change in number or size of cNFs during prior pregnancies. More than half (64/105) of the women reported that new cNFs developed during pregnancy, but multiparous women did not have new tumors develop during all pregnancies. Lammert et al. ${ }^{48}$ distributed a survey to 59 women with NF1 who had used hormone contraceptives to evaluate the effect of exogenous estrogen and progesterone on the development or proliferation of cNFs while on these drugs. The majority (53/58) of women reported no change in cNFs, but 5 reported new cNFs and growth of existing ones. Although interesting, these studies are inconclusive as they suffer from their retrospective and subjective nature. Notably, Schwann cells derived from human neurofibromas express progesterone receptors, and they have elevated proliferation rates when exposed to progesterone in vitro. ${ }^{49}$ Further, Le et al. ${ }^{4}$ showed that implantation of $\mathrm{Nf1}^{-/-}$SKPs resulted in development of $\mathrm{cNFs}$ only in pregnant $\mathrm{CMV}-\mathrm{Cre} \mathrm{ERT2}^{\mathrm{N}} \mathrm{Nf1}^{\mathrm{fl}-}$ mice, adding preclinical data to the working hypothesis of an association between sex hormone exposure and cNF development in female patients. However, Sbidian et al. ${ }^{50}$ analyzed prospective data collected between 2002 and 2005 from adults (mean age $36 \pm 14$ years) with NF1 to assess difference in growth and number of $\mathrm{cNF}$ between sexes and between nulliparous and parous women. Men were at higher risk of developing subcutaneous neurofibromas regardless of age, but there was no difference in the 
number of cNFs between men and women after the age of 40, regardless of the parous status of the women. Overall these data indicate that there may be a role of sex hormones in development of cNF; however, they are not causative or even dominant. Prospective epidemiologic case-control studies that address different phases of hormonal changes in women with concurrent assays of systemic hormonal levels (i.e., during exogenous hormone exposure, pregnancy, and in menopause) are important for understanding of the role of hormones at different phases of cNF development clinically.

\section{Challenges in establishing in vitro and in vivo models representing human cNF}

Developing cNF models will be critical to further elucidate their biology and to serve as preclinical models for therapeutic testing. However, there are many challenges in establishing in vitro and in vivo models of human cNF. First, genetically, cNF initiation and progression must associate with NF1 loss. Tumor development should be driven by specific changes in known pathways involved in human cNF, and tumor gene expression profiles should resemble those of human cNF. Second, biologically, cNFs develop through multistage progression (initiation, proliferation/progression, and quiescence). The cNF models should initiate from a small group of cells of origin that harbor NF1 loss, and the tumor histology and pathology should be similar to human cNF. In addition, tumor development should require similar microenvironmental factors as in human cNF. Third, therapeutically, new cNF models should be robust for the preclinical testing of inhibitors directed at pathways critical for cNF development that can lead to clinical trials in humans. To better understand the role of the tumor microenvironment on the development and proliferation of $\mathrm{cNF}$, future studies should identify what extrinsic signals regulate cNF formation, which includes understanding the cell source of these signals, the timing of these signals, if biallelic inactivation in the cells is important, and elucidating the role of soluble signaling molecules, ECM, and cell contact.

\section{Discussion}

Analysis of NF1 patient tumors and mouse models has led to the conclusion that the loss of function of NF1/Nf1 is an early and necessary step in the development of neurofibromas. However, we do not know what further triggers or modifies neurofibroma growth to yield the wide range of intrapatient and interpatient variability that is seen. Assuming different cellular origins for the different phenotypic manifestations of the disease, it is possible that the different thresholds for functional NF1 from one cell type to another explain the variable phenotypes observed: melanocytes (CALMS, Lisch nodules $)<\mathrm{cNF}$ cell of origin $(\mathrm{cNF})<$ Schwann cell lineage (pNF). This hypothesis would explain why even mildly affected patients with NF1 have CALMS, why patients with severe pNF almost always carry CALMS and cNF, and why the phenotypic manifestations have different temporal onset. Each NF1 DNA mutation potentially has more or less consequence because it leaves neurofibromin with more or less residual function and some cell types are more dependent on NF1 function than others. Importantly, this theory does not exclude a role for the tumor microenvironment and more study is needed here.

As we progress in our quest to decipher the biology of cNF, it remains important to compare and contrast $\mathrm{cNF}$ and $\mathrm{pNF}$ in terms of cellular origin, NF1 genotype and modifiers, cellular composition, and the effect of tumor microenvironment, as well as the effects of sex hormones. A top priority is to continue to gather large repositories of NF1-driven neurofibromas with annotated clinical data so that correlations can be delineated. Finally, analysis of these biospecimens should be expanded by including transcriptomic, proteomic, and epigenetic profiling through unified collaborative approaches to accelerate discovery most efficiently.

\section{Author contributions}

J.P. Brosseau: collection of data, drafting of the manuscript. D.C. Pichard: collection of data, drafting of the manuscript. E. Legius: review of manuscript, development of recommendations. P. Wolkenstein: review of manuscript, development of recommendations. RM Lavker: review of manuscript, development of recommendations. J. Blakeley: drafting and review of manuscript, development of recommendations. V.M. Riccardi: contributing to and review of manuscript, development of recommendations. S. Verma: drafting and review of manuscript, development of recommendations. I. Brownell: drafting and review of manuscript, development of recommendations. L. Le: drafting and review of manuscript, development of recommendations, subgroup leadership.

\section{Acknowledgment}

The authors thank fellow cNF summit participants Richard Anderson, Naba Bora, Denise Casey, Sally Gottesman, Rhonda Jackson, Kurt Jarnagin, Pam Knight, Hon Sum Ko, Bruce Korf, Salvo LaRosa, Jill Morris, Michael Parides, Scott Plotkin, Ken Rudd, Marigo Stathis, Hubert Weinberg, and Brigitte Widemann for their contributions.

\section{Study funding}

This work was supported by an agreement from The Johns Hopkins University School of Medicine and the Neurofibromatosis Therapeutic Acceleration Program (NTAP). Its contents are solely the responsibilities of the authors and do not necessarily represent the official views of The Johns Hopkins University School of Medicine.

\section{Disclosure}

J. Brosseau receives support as a 2016 Children's Tumor Foundation Young Investigator Awardee. D. Pichard is funded through the Intramural Research Program of the NCI Center for Cancer Research. The opinions expressed here are her own and do not reflect the views of the NIH. E. Legius and P. Wolkenstein report no disclosures relevant to the manuscript. R. Lavker receives funding from the NIH. J. Blakeley, V. Riccardi, and S. Verma report no disclosures relevant to the 
manuscript. I. Brownell has nothing to disclose; the opinions expressed here are his own and do not reflect the views of the NIH. L. Le holds a Career Award for Medical Scientists from the Burroughs Wellcome Fund and receives funding from the National Cancer Institute of the NIH (grant number R01 CA166593) and the US Department of Defense. Go to Neurology.org/N for full disclosures.

Received November 1, 2017. Accepted in final form April 9, 2018.

\section{References}

1. Wallace MR, Marchuk DA, Andersen LB, et al. Type 1 neurofibromatosis gene: identification of a large transcript disrupted in three NF1 patients. Science 1990;249: $181-186$.

2. Rad E, Tee AR. Neurofibromatosis type 1: fundamental insights into cell signalling and cancer. Semin Cell Dev Biol 2016;52:39-46.

3. Liao CP, Pradhan S, Chen Z, Patel AJ, Booker RC, Le LQ. The role of nerve microenvironment for neurofibroma development. Oncotarget 2016;7:61500-61508.

4. Le LQ, Shipman T, Burns DK, Parada LF. Cell of origin and microenvironment contribution for NF1-associated dermal neurofibromas. Cell stem cell 2009;4:453-463.

5. Karvonen SL, Kallioinen M, Yla-Outinen H, Poyhonen M, Oikarinen A, Peltonen J. Occult neurofibroma and increased $\mathrm{S} 100$ protein in the skin of patients with neurofibromatosis type 1: new insight to the etiopathomechanism of neurofibromas. Arch Dermatol 2000;136:1207-1209.

6. Gresset A, Coulpier F, Gerschenfeld G, et al. Boundary caps give rise to neurogenic stem cells and terminal glia in the skin. Stem Cell Rep 2015;5:278-290.

7. Fernandes KJ, McKenzie IA, Mill P, et al. A dermal niche for multipotent adult skinderived precursor cells. Nat Cell Biol 2004;6:1082-1093.

8. Jessen KR, Mirsky R. The origin and development of glial cells in peripheral nerves. Nat Rev Neurosci 2005;6:671-682.

9. Adameyko I, Lallemend F, Aquino JB, et al. Schwann cell precursors from nerve innervation are a cellular origin of melanocytes in skin. Cell 2009;139:366-379.

10. Giorno R, Lieber J, Claman HN. Ultrastructural evidence for mast cell activation in a case of neurofibromatosis. Neurofibromatosis 1989;2:35-41.

11. Staser K, Yang FC, Clapp DW. Mast cells and the neurofibroma microenvironment. Blood 2010;116:157-164.

12. Zhu Y, Ghosh P, Charnay P, Burns DK, Parada LF. Neurofibromas in NF1: Schwann cell origin and role of tumor environment. Science 2002;296:920-922.

13. Yang FC, Ingram DA, Chen S, et al. Neurofibromin-deficient Schwann cells secrete a potent migratory stimulus for Nf1+/- mast cells. J Clin Invest 2003;112:1851-1861.

14. Yang FC, Chen S, Clegg T, et al. Nf1+/- mast cells induce neurofibroma like phenotypes through secreted TGF-beta signaling. Hum Mol Genet 2006;15:2421-2437.

15. Robertson KA, Nalepa G, Yang FC, et al. Imatinib mesylate for plexiform neurofibromas in patients with neurofibromatosis type 1: a phase 2 trial. Lancet Oncol 2012; 13:1218-1224.

16. Riccardi VM. Ketotifen suppression of NF1 neurofibroma growth over 30 years. Am J Med Genet A 2015;167:1570-1577.

17. Prada CE, Jousma E, Rizvi TA, et al. Neurofibroma-associated macrophages play roles in tumor growth and response to pharmacological inhibition. Acta Neuropathol 2013; 125:159-168.

18. Kalluri R, Zeisberg M. Fibroblasts in cancer. Nat Rev Cancer 2006;6:392-401.

19. Rogler G. New therapeutic avenues for treatment of fibrosis: can we learn from other diseases? Dig Dis 2014;32(suppl 1):39-49.

20. Peltonen J, Penttinen R, Larjava H, Aho HJ. Collagens in neurofibromas and neurofibroma cell cultures. Ann NY Acad Sci 1986;486:260-270.

21. Widemann BC, Babovic-Vuksanovic D, Dombi E, et al. Phase II trial of pirfenidone in children and young adults with neurofibromatosis type 1 and progressive plexiform neurofibromas. Pediatr Blood Cancer 2014;61:1598-1602.

22. Babovic-Vuksanovic D, Ballman K, Michels V, et al. Phase II trial of pirfenidone in adults with neurofibromatosis type 1 . Neurology 2006;67:1860-1862.

23. Kuroda K, Tajima S. HSP47 is a useful marker for skin fibroblasts in formalin-fixed, paraffin-embedded tissue specimens. J Cutan Pathol 2004;31:241-246.
24. Peltonen J, Hsiao LL, Jaakkola S, et al. Activation of collagen gene expression in keloids: co-localization of type I and VI collagen and transforming growth factor-beta 1 mRNA. J Invest Dermatol 1991;97:240-248.

25. Dundr P, Povysil C, Tvrdik D. Actin expression in neural crest cell-derived tumors including schwannomas, malignant peripheral nerve sheath tumors, neurofibromas and melanocytic tumors. Pathol Int 2009;59:86-90.

26. Riccardi VM. Cutaneous manifestation of neurofibromatosis: cellular interaction, pigmentation, and mast cells. Birth Defects Orig Artic Ser 1981;17:129-145.

27. Chen Z, Pradhan S, Liu C, Le LQ. Skin-derived precursors as a source of progenitors for cutaneous nerve regeneration. Stem Cells 2012;30:2261-2270.

28. Salgado C, Vilson F, Miller NR, Bernstein SL. Cellular inflammation in nonarteritic anterior ischemic optic neuropathy and its primate model. Arch Ophthalmol 2011 129:1583-1591.

29. Burnett MG, Zager EL. Pathophysiology of peripheral nerve injury: a brief review. Neurosurg Focus 2004;16:E1.

30. Zochodne DW. Neurobiology of Peripheral Nerve Regeneration. New York: Cambridge University Press; 2008.

31. Ortonne N, Wolkenstein P, Blakeley JO, et al. Cutaneous neurofibromas: current clinical and pathologic issues. Neurology 2018;91:S5-S13.

32. Friedrich RE, Holstein AF, Middendorff R, Davidoff MS. Vascular wall cells contribute to tumourigenesis in cutaneous neurofibromas of patients with neurofibromatosis type 1: a comparative histological, ultrastructural and immunohistochemical study. Anticancer Res 2012;32:2139-2158.

33. Texeira MS, Duraes S, Pereira LA, Pantaleao L. Multiple cutaneous lipomatous neurofibromas. Dermatol Online J 2016:22.

34. Upadhyaya M, Huson SM, Davies M, et al. An absence of cutaneous neurofibromas associated with a 3-bp inframe deletion in exon 17 of the NF1 gene (c.2970-2972 delAAT): evidence of a clinically significant NF1 genotype-phenotype correlation. Am J Hum Genet 2007;80:140-151.

35. Rojnueangnit $\mathrm{K}$, Xie J, Gomes A, et al. High incidence of Noonan syndrome features including short stature and pulmonic stenosis in patients carrying NF1 missense mutations affecting p.Arg 1809: genotype-phenotype correlation. Hum Mutat 2015; 36:1052-1063.

36. Kehrer-Sawatzki H, Mautner VF, Cooper DN. Emerging genotype-phenotype relationships in patients with large NF1 deletions. Hum Genet 2017;136:349-376.

37. Brems H, Chmara M, Sahbatou M, et al. Germline loss-of-function mutations in SPRED1 cause a neurofibromatosis 1-like phenotype. Nat Genet 2007;39: 1120-1126.

38. Messiaen L, Yao S, Brems H, et al. Clinical and mutational spectrum of neurofibromatosis type 1-like syndrome. JAMA 2009;302:2111-2118.

39. De Raedt T, Beert E, Pasmant E, et al. PRC2 loss amplifies Ras-driven transcription and confers sensitivity to BRD4-based therapies. Nature 2014;514:247-251.

40. Ars E, Serra E, Garcia J, et al. Mutations affecting mRNA splicing are the most common molecular defects in patients with neurofibromatosis type 1 . Hum Mol Genet 2000;9:237-247.

41. Sabbagh A, Pasmant E, Imbard A, et al. NF1 molecular characterization and neurofibromatosis type I genotype-phenotype correlation: the French experience. Hum Mutat 2013;34:1510-1518.

42. Xu W, Yang X, Hu X, Li S. Fifty-four novel mutations in the NF1 gene and integrated analyses of the mutations that modulate splicing. Int J Mol Med 2014;34:53-60.

43. Heim RA, Silverman LM, Farber RA, Kam-Morgan LN, Luce MC. Screening for truncated NF1 proteins. Nat Genet 1994;8:218-219.

44. Heim RA, Kam-Morgan LN, Binnie CG, et al. Distribution of 13 truncating mutations in the neurofibromatosis 1 gene. Hum Mol Genet 1995;4:975-981.

45. Gosline SJ, Weinberg $\mathrm{H}$, Knight $\mathrm{P}$, et al. A high-throughput molecular data resource for cutaneous neurofibromas. Sci Data 2017;4:170045.

46. Riccardi VM. Translational Genetics, Genomics: the fundamental nature of NF1 neurofibromas. J Translational Genet Genomics 2017:1-12.

47. Dugoff L, Sujansky E. Neurofibromatosis type 1 and pregnancy. Am J Med Genet 1996;66:7-10.

48. Lammert M, Mautner VF, Kluwe L. Do hormonal contraceptives stimulate growth of neurofibromas? A survey on 59 NF1 patients. BMC Cancer 2005;5:16.

49. Fishbein L, Zhang X, Fisher LB, et al. In vitro studies of steroid hormones in neurofibromatosis 1 tumors and Schwann cells. Mol Carcinog 2007;46:512-523.

50. Sbidian E, Duong TA, Valeyrie-Allanore L, Wolkenstein P. Neurofibromatosis type 1: neurofibromas and sex. Br J Dermatol 2016;174:402-404. 


\section{Neurology}

\section{The biology of cutaneous neurofibromas: Consensus recommendations for setting research priorities}

Jean-Philippe Brosseau, Dominique C. Pichard, Eric H. Legius, et al. Neurology 2018;91;S14-S20

DOI 10.1212/WNL.0000000000005788

\section{This information is current as of July 9, 2018}

\section{Updated Information \&} Services

\section{References}

Subspecialty Collections

Permissions \& Licensing

Reprints including high resolution figures, can be found at: http://n.neurology.org/content/91/2_Supplement_1/S14.full

This article cites 47 articles, 4 of which you can access for free at: http://n.neurology.org/content/91/2_Supplement_1/S14.full\#ref-list-1

This article, along with others on similar topics, appears in the following collection(s):

\section{Nerve tumor}

http://n.neurology.org/cgi/collection/nerve_tumor

Information about reproducing this article in parts (figures,tables) or in its entirety can be found online at:

http://www.neurology.org/about/about_the_journal\#permissions

Information about ordering reprints can be found online:

http://n.neurology.org/subscribers/advertise

Neurology ${ }^{\circledR}$ is the official journal of the American Academy of Neurology. Published continuously since 1951, it is now a weekly with 48 issues per year. Copyright $@ 2018$ The Author(s). Published by Wolters Kluwer Health, Inc. on behalf of the American Academy of Neurology.. All rights reserved. Print ISSN: 0028-3878. Online ISSN: 1526-632X.

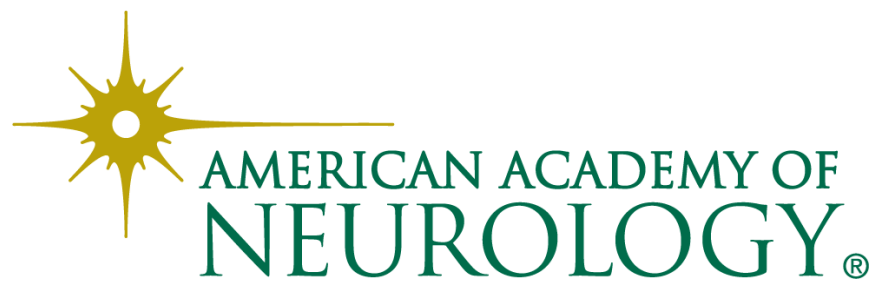

